\title{
Daily stair climbing is associated with decreased risk for the metabolic syndrome
}

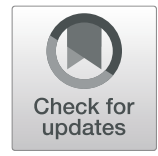

\author{
Anna C. Whittaker ${ }^{1,2^{*}}$, Frank F. Eves ${ }^{2,3}$, Douglas Carroll ${ }^{2}$, Tessa J. Roseboom ${ }^{4,5}$, Annie T. Ginty ${ }^{6}$, \\ Rebecca C. Painter ${ }^{4}$ and Susanne R. de Rooij ${ }^{5}$
}

\begin{abstract}
Background: Stair climbing can be a vigorous lifestyle physical activity, and is associated with healthier lipoprotein profiles, lower body weight and blood pressure, as well as higher aerobic fitness. The present analysis of data from a cohort of late middle-aged men and women examined the association between daily stair climbing and the metabolic syndrome.

Methods: Data from 782 (423 women) participants (mean (SD) age 58.3 (0.95) years in the Dutch Famine Birth Cohort Study (2002-2004) were used to examine the cross-sectional association between self-reported daily stair climbing and the metabolic syndrome. Stair climbing was assessed by the question 'Do you climb stairs daily?' and the metabolic syndrome was defined using the established five components relating to lipid fractions, blood glucose levels, blood pressure and abdominal obesity.

Results: Not climbing stairs daily was associated with an increased incidence of the metabolic syndrome (OR= $1.90,95 \% \mathrm{Cl}=1.23,2.92, p=0.004)$ and a greater number of its components $\left(F_{1,780}=8.48, p=0.004\right)$ : these associations were still evident after adjusting for a variety of potential confounders.

Conclusions: The most likely explanation for the current findings is that daily stair climbing may be protective against the metabolic syndrome. This result reinforces public health recommendations for increased stair climbing with evidence from physiological outcomes.
\end{abstract}

Keywords: Cohort study, Metabolic health, Public health, Stairs

\section{Introduction}

New global and national guidance on physical activity suggests that the benefits of physical activity can be accrued across the day [1-3] whereas previously it was thought that activity bouts needed to be of at least 10 min in duration to effect any positive change in health and older guidelines had this recommendation built in [3]. This move towards emphasizing the importance of the accumulation of daily physical activity minutes

\footnotetext{
* Correspondence: a.c.whittaker@stir.ac.uk

${ }^{1}$ SpHERE, Faculty of Health Sciences and Sport, University of Stirling, Stirling FK9 4LA, UK

${ }^{2}$ School of Sport, Exercise and Rehabilitation Sciences, University of Birmingham, Birmingham, UK

Full list of author information is available at the end of the article
}

means that even brief bursts of physical activity, such as stair climbing, may be important in maintaining health and wellbeing. Importantly, such brief bouts of activity as part of everyday life may be more feasible for some individuals than formal exercise sessions. This study reports secondary analyses of data from the Dutch Famine Birth Cohort. The analyses here address a very specific question about brief daily physical activity; is daily stair use protective for cardio-metabolic health?

Climbing stairs can be a vigorous lifestyle physical activity, requiring 9.6 times the energy consumption of sitting for a continuous climb in the field [4] and 8.6 times that of sitting in laboratory conditions when climbing slowly, i.e., 70 steps per minute [5]. The raising of one's

(C) The Author(s). 2021 Open Access This article is licensed under a Creative Commons Attribution 4.0 International License, which permits use, sharing, adaptation, distribution and reproduction in any medium or format, as long as you give appropriate credit to the original author(s) and the source, provide a link to the Creative Commons licence, and indicate if changes were made. The images or other third party material in this article are included in the article's Creative Commons licence, unless indicated otherwise in a credit line to the material. If material is not included in the article's Creative Commons licence and your intended use is not permitted by statutory regulation or exceeds the permitted use, you will need to obtain permission directly from the copyright holder. To view a copy of this licence, visit http://creativecommons.org/licenses/by/4.0/ The Creative Commons Public Domain Dedication waiver (http://creativecommons.org/publicdomain/zero/1.0/) applies to the data made available in this article, unless otherwise stated in a credit line to the data. 
weight against gravity when climbing is an energetically costly behavior which has been objectively characterized as light to vigorous activity depending on intensity and duration; its intensity tends to be underestimated in selfreports [6]. For example, stair climbing and descending at a self-selected pace was reported to be light to vigorous in intensity, and only vigorous during a 10-min but not 1- or 3-min bout. Undoubtedly, inclusion of the lower intensity activity of stair decent in the protocol [4] and testing of a highly fit sample would contribute to subjective reports of light in intensity [7]. Despite this variation in intensity, experimental studies show that increased volumes of stair climbing are associated with improved lipoprotein profiles, reduced weight, blood pressure and fasting blood glucose, as well as increased aerobic fitness and leg strength [7-9]. Additionally, there can be a reduced post-prandial glucose-response to a meal [6]. In observational data, those who report more frequent stair climbing have a decreased risk of coronary heart disease and stroke $[8,10,11]$. Unsurprisingly given its potential benefits, increased volumes of stair climbing are a public health target for many health organizations in the developed world [12-14].

The metabolic syndrome (MetS) is a cluster of symptoms (abdominal adiposity, high triglyceride levels, low levels of high density lipoprotein (HDL) cholesterol, elevated blood pressure, and high levels of fasting blood glucose or diabetes) that increases the risk of cardiovascular disease and all-cause mortality $[15,16]$. Although the association between stair climbing and MetS is unknown, the range of beneficial outcomes above certainly suggest that regular stair climbing should be linked to lower risk [9]. Data from the Dutch Famine Birth Cohort allowed us to examine this hypothesis. The paper uses the answer to a single question in the interview about daily stair use to test the utility of the behavior for physiological outcomes.

\section{Methods \\ Participants}

In this secondary analysis study, Seven hundred eightytwo Seven participants from the Dutch Famine Birth Cohort (423 women, 359 men), who were born in Amsterdam between November 1943 and February 1947 , completed a clinical examination in 2002-4. The primary analyses investigated the effects of reduced energy intake by a mother on the health outcomes for their foetus in adulthood, i.e. prenatal exposure to famine in 1944-1945 [17]. Details are available elsewhere [17, 18], but briefly the cohort were recruited by tracing 5425 people born between November, 1943, and February, 1947 in the Wilhelmina Gasthuis, hospital in Amsterdam, for whom detailed records of the course of gestation and birth from records from the
Gemeentearchief (city archive) of Amsterdam were retrieved. The mean caloric rations during the famine were as low as $400-800 \mathrm{cal}$ per day. Following exclusion of those without complete records, this cohort included 2414 singleton liveborns. In 1995, cohort members who were still living in the Netherlands and whose address was known to the investigators were invited to participate in a study on the association between prenatal exposure to the Dutch famine and cardio-metabolic health in later life. In 2002, of the group of 1423 eligible people, 810 agreed to participate, with 782 included in the present analysis having complete data on clinical and stair climbing variables. Fuller details on the whole cohort are published elsewhere $[17,19]$.

Mean (SD) age at the time of the examination was $58.34(0.95)$ years. The study was approved by the appropriate Ethics Committee and conducted in accordance with the declaration of Helsinki. Participants provided informed written consent.

\section{Measurements}

Measurements were taken by trained nurses. Stair climbing was assessed with the simple question 'Do you climb stairs daily?' (yes/no). Participants indicated whether they participated in sport for at least an hour each fortnight and their smoking status (current smoker, exsmoker, never smoker), two lifestyle factors previously associated with MetS risk. For self-reported health, participants rated their health as excellent, very good, good, mediocre or poor [20]. Socio-economic position was measured using the Dutch occupation-based International Socio-economic Index-92 (ISEI-92), a numeric scale based on the person's or their partner's occupation, whichever status was higher [21], and marital status was assessed. Participants revealed whether they were taking medication for diabetes and/or hypertension. Triglycerides and HDL were assessed using an enzymatic colorimetric reagent on a P-800 Roche analyzer and plasma glucose levels determined by photometric assay using a Roche Modular P analyzer. Waist circumference was measured by tape midway between the costal margin and the iliac crest. Blood pressure was recorded twice, using an Omron 705 sphygmomanometer and the average value computed. MetS was defined as having at least three of the following: triglyceride levels $\geq 1.7 \mathrm{mmol} / \mathrm{L}$; $\mathrm{HDL}<1.3 \mathrm{mmol} / \mathrm{L}$ for women and $<1.03 \mathrm{mmol} / \mathrm{L}$ for men; glucose levels $\geq 5.6 \mathrm{mmol} / \mathrm{L}$ and/or taking medication for diabetes; waist circumference $\geq 80$ for women and $\geq 94 \mathrm{~cm}$ for men; blood pressure $\geq 130 / 85 \mathrm{mmHg}$ or taking anti-hypertensive medication [22].

The famine period was defined according to the daily official food rations for the general population aged $>21$ years. The official rations accurately reflect the variation over time in the total amount of food available in the 
west of the Netherlands. Foetuses were considered to have been exposed to famine if the average daily rations during any 13-week period of gestation were $<1000 \mathrm{cal}$, so babies born between 7 January and 8 December 1945 were considered exposed. Periods of 16 weeks each were used to differentiate between people who had been exposed in late gestation (born between 7 January and 28 April 1945), in mid-gestation (born between 29 April and 18 August 1945), and in early gestation (born between 19 August and 8 December 1945). People born before 7 January 1945 and conceived after 8 December 1945 were considered unexposed [19].

\section{Statistical analysis}

Comparisons between stair climbing groups and between those with and without MetS were undertaken using ANOVA and $x^{2}$. The association between stair climbing and MetS was tested using logistic regression, first in an unadjusted model and then in a model that adjusted for age, sex, socioeconomic position, marital status, smoking, self-reported health and sports participation, and famine exposure; for the last of these, famine exposure in the first trimester was compared to later and no prenatal exposure, as it was for the first trimester that health effects tended to occur [23]. Logistic regression was also used to examine MetS components and daily stair climbing. ANOVA and ANCOVA, using covariates above, tested the association between stair climbing and the number of MetS components.

\section{Results}

The characteristics of those with and without MetS and of those who reported that they did and did not climb stairs daily are presented in Table 1. Those who did not climb stairs daily were at greater risk for MetS in unadjusted $(\mathrm{OR}=1.90,95 \% \mathrm{CI}=1.23,2.92$, $p=0.004)$, and adjusted models $(\mathrm{OR}=1.72,95 \% \mathrm{CI}=$ $1.12,2.64, p=0.01)$. The multivariate analysis also revealed that MetS was more common in men, in those with poorer self-reported health, and in those who did not participate in sports (see Table 2). The MetS components that contributed most to its association with stair climbing were high blood glucose, $(\mathrm{OR}=$ $1.7395 \%$ CI-1.12, 2.66, $p=0.01)$, triglycerides, $(\mathrm{OR}=$ $1.4995 \% \mathrm{CI}=0.98,2.28, p=0.07)$, and blood pressure $(\mathrm{OR}=1.5095 \% \mathrm{CI}=0.94,2.39, p=0.09)$. Not climbing stairs daily was also associated with an increased number of MetS components, in ANOVA, $\left(\mathrm{F}_{1,780}=\right.$ 8.48, $p=0.004)$ and in ANCOVA $\left(\mathrm{F}_{1,760}=6.96, p=\right.$ 0.009). Again, in the multivariate analysis, effects of reporting not climbing stairs survived the addition of the adverse effects of male sex, poor self-reported health, and no sports participation.

Table 1 Characteristics of participants with and without MetS and who climb or do not climb stairs every day

\begin{tabular}{|c|c|c|c|c|c|c|}
\hline \multirow[t]{2}{*}{ Variable } & $\begin{array}{l}\text { No MetS } \\
(N=402)\end{array}$ & $\begin{array}{l}\text { MetS } \\
(N=380)\end{array}$ & $p$ & $\begin{array}{l}\text { Daily Stairs } \\
\text { Stairs } \\
(N=676)\end{array}$ & $\begin{array}{l}\text { Not Daily } \\
(N=106)\end{array}$ & $p$ \\
\hline & \multicolumn{3}{|c|}{ Mean (SD) / N (\%) } & \multicolumn{3}{|c|}{ Mean (SD) / N (\%) } \\
\hline Sex (Male) & $167(42)$ & $192(51)$ & .01 & $315(47)$ & $44(42)$ & .33 \\
\hline Age (years) & $58.4(0.96)$ & $58.3(0.94)$ & .40 & $58.3(0.94)$ & $58.4(1.03)$ & .60 \\
\hline \multicolumn{7}{|l|}{ Marital Status } \\
\hline Married & $303(76)$ & $294(78)$ & .92 & $527(78)$ & $70(66)$ & .09 \\
\hline Divorced & $45(11)$ & $38(10)$ & & $66(10)$ & $17(16)$ & \\
\hline Widowed & $21(5)$ & $18(5)$ & & $32(5)$ & $7(7)$ & \\
\hline Never married & $32(8)$ & $29(8)$ & & $49(7)$ & $12(11)$ & \\
\hline Socio-economic status & $50.2(14.14)$ & $49.2(14.23)$ & .33 & $50.0(14.35)$ & $48.2(13.02)$ & .22 \\
\hline \multicolumn{7}{|l|}{ Smoking } \\
\hline Smoker & $98(24)$ & $94(25)$ & .03 & $156(23)$ & $36(34)$ & .04 \\
\hline Ex-smoker & $144(36)$ & $166(44)$ & & $270(40)$ & $40(39)$ & \\
\hline Never smoker & $160(40)$ & $119(31)$ & & $249(37)$ & $30(27)$ & \\
\hline Self-reported health (reverse-scored) & $2.8(0.85)$ & $3.1(0.88)$ & $<.001$ & $2.9(0.86)$ & $3.2(0.95)$ & .02 \\
\hline Sports participation (Yes) & $253(63)$ & $184(48)$ & $<.001$ & $380(56)$ & $57(54)$ & .63 \\
\hline Famine exposure in 1st trimester (Yes) & $36(9)$ & $38(10)$ & .62 & $62(9)$ & $12(11)$ & .48 \\
\hline MetS (Yes) & - & - & - & $315(47)$ & $65(61)$ & $<.01$ \\
\hline MetS ( $\mathrm{N}$ of components) & $1.4(0.71)$ & $3.5(0.66)$ & $<.001$ & $2.4(1.27)$ & $2.8(1.17)$ & $<.01$ \\
\hline Daily stair climbing (Yes) & $361(90)$ & $315(83)$ & $<.01$ & - & - & - \\
\hline
\end{tabular}


Table 2 Contributors to the presence of MetS in the multivariate analysis

\begin{tabular}{llll}
\hline Variable & OR & 95\% Cls & $\boldsymbol{p}$ \\
\hline Sex (Male) & 1.464 & $1.088-1.969$ & .01 \\
Age (years) & 0.924 & $0.791-1.079$ & .32 \\
Marital status & 0.916 & $0.774-1.084$ & .31 \\
Socio-economic status & 1.000 & $0.989-1.011$ & .98 \\
Famine exposure, 1st trimester (Yes) & 1.114 & $0.671-1.850$ & .68 \\
Self-reported health (reverse scored) & 1.366 & $1.444-1.631$ & $<.01$ \\
Smoking status & 0.938 & $0.772-1.141$ & .52 \\
Sport participation (No) & 1.580 & $1.167-1.490$ & $<.01$ \\
Daily stairs (No) & 1.725 & $1.117-2.663$ & .01 \\
\hline
\end{tabular}

\section{Discussion}

Not reporting daily stair climbing was associated with an increased incidence of MetS and possession of an increased number of MetS components. This result is consistent with experimental effects of stair climbing on risk factors for the metabolic syndrome $[6,8,9,24]$ and associations between reported stair use and cardiovascular disease outcomes $[8,10]$. Although stair climbing behavior was assessed by self-report, the specificity and simplicity of the posed question was unambiguous; do you climb stairs daily? Responding no to this simple query was associated with increased MetS risk. We can think of no self-presentational reasons for reporting that one does not climb stairs. Finally, avoiding stair climbing on a daily basis can only be achieved by residential circumstance such that one lives on the ground floor, uses no stairs on their commute to work, i.e., chooses the escalator, or selects the lift in their workplace. Observational studies reveal that predominantly, stairs are avoided when there is an alternative means of ascent [25-27] (combined $n=1,232,709$ ), more so by older individuals and the female sex, the participants measured in this study [25-27]. The results of the secondary analyses here suggest that ground floor living may be an unhealthy residential choice, and that, where it is within an individual's control, using stairs in daily commutes or activity and in the workplace would be beneficial for health.

Reverse causation cannot be fully discounted. Individuals in poor health may move from residences with stairs to ground floor accommodation. Set against this interpretation, the association between stair climbing and MetS survived adjustment for self-reported health. Further, reverse causation is rendered less likely given that it was the more unseen components -blood glucose, triglycerides, blood pressure - rather than the more evident one, abdominal adiposity, that appear to be implicated. We adjusted for the potential socio-demographic factors of sex and SES; adjustment for age was inappropriate, given the restricted range in this birth cohort design. Additionally, we adjusted for two behavioral risk factors for MetS, smoking and formal exercise participation, making confounding less likely, although not impossible. The absence of differences between stair climbing sub-groups on sport participation in Table 1 suggests effects of the two physical activity behaviors are independent. However, we acknowledge that sport participation measurement might not have picked up on other confounders, such as the beneficial physical activities of walking or cycling that may occur without being formal exercise. In a recent experimental test, walking up and down stairs at home at a self-selected pace 5 days a week improved the MetS risk factors of body fat, triglycerides, HDL cholesterol and blood glucose [9]. Obviously in residential locations, stair ascent would be followed by a subsequent stair descent which may add to the benefits possible from stair climbing alone [9]. The most plausible explanation for the present results is that daily stair climbing protects against MetS.

It should be acknowledged that a single question, binary subjective measure of stair climbing is a limitation of this research. Although simple, the yes/no question utilized here does not give detail on the frequency of stair climbing each day, the number of flights climbed, and the intensity of climbing. Additionally, a single question cannot assess whether participants maintained this behavior, or any variation in climbing across the week, e.g., such as someone who climbs stairs at work 5 days a week but does not use stairs at the weekend. As noted above, however, stair climbing is typically avoided at work [26], with avoidance more frequent in overweight individuals that would be more likely to have MetS. Detailed interviewing would have allowed for much more nuanced analyses in terms of stair climbing dosage for effects on health. The objective observation of stair climbing utilized in many quasi-experimental designs e.g. [27],, naturally would remove the doubts about reliability inherent in all subjective self-report measures, and specifically the under-estimation of intensity that may be occurring in stair climbing self-reports [24]. That being said, that we still find an association even with this simple measure suggests that the impact of stair climbing is considerable, and opens up the field for further research into aspects such as dose-response relationships. This is supported by recent research showing that even subjectively-reported 'light' and short bouts of stair climbing can affect the metabolic response to a meal [24], and this response is not influenced by underlying cardio-respiratory fitness [28]. This also draws attention to the possible attenuation of the post-prandial glucose peak which may be one plausible mechanism by which stair climbing helps reduce the risk of MetS. 
Although the current sample is somewhat unusual in its recruitment regarding the Dutch famine exposure, we believe it is unlikely that the famine exposure element of this cohort limits the generalizability of the present results given that not all of the sample were famine exposed, and famine exposure did not significantly influence metabolic syndrome in this sample [17]. Further, we do not believe that the age of these data affects the current relevance of these findings, as both sedentary behavior and the metabolic syndrome are common, if not increasingly so today. However, these results could be regarded as preliminary until further longitudinal research is able to confirm these associations.

Encouragingly, stair climbing interventions are one of the few physical activity initiatives that repeatedly change behavior $[29,30]$. It has been estimated that the increased energy consumption from these interventions is six times more cost-effective than their nearest competitor [31]. There is, however, a practical limitation to stair climbing as a plausible approach to increasing public health. The relatively brief duration of a single stair climbing episode in public access settings means that the behavior might have minimal effects on overall accumulation of physical activity during daily life [26, 31, 32]. Instead, repeated stair climbing at work, or in the home environment as reported here, would allow daily accumulation of stair climbing episodes [26, 32] . Unlike formal exercise sessions such as sport, stair climbing is a plausible behavior for most of the population. No particular skills are required, there is no competition, and there are few presentational concerns. Importantly, there are no time barriers to stair climbing, a frequent reason given for insufficient participation in other types of physical activity. Indeed, greater effects of stair climbing interventions have been reported in the overweight, suggesting that it is a physical activity that is acceptable to those at greater risk of MetS [32, 33]. Finally, research suggests that it is the intensity of physical activity, rather than its duration, that may be more important for MetS [34-36]. In this respect, the vigorous nature of stair climbing may be a particularly beneficial property of this lifestyle activity, particularly given that individuals tend to underestimate how intense stair climbing may actually be [6]. Stair climbing is promoted for its potential health benefits, despite relatively limited evidence of efficacy on health outcomes. Here, we report associations between daily stair use and physiological markers of cardio-metabolic health.

\section{Acknowledgements}

We thank the participants for their willing cooperation.

\section{Authors' contributions}

$D C$ and FE conceived of the original analysis idea, SdR, TR and RP shared the dataset, SdR, FE \& DC conducted analysis and wrote the Results. DC, FE, AW, $S d R, T R, A G$, and RP all contributed to the full first draft and various versions of the manuscript. AW updated the manuscript and formatted the final draft for submission. AW, FE, SdR and AG worked on the revision and the final revised manuscript was approved by all authors.

\section{Funding}

The present study was supported by the Netherlands Heart Foundation (grant numbers 2001B087 and 2003B165). The funding source had no role in study design, data collection, analysis and interpretation of the data.

\section{Availability of data and materials}

The Dutch famine birth cohort study welcomes opportunities for collaboration; enquiries should be directed to the principal investigator (t.j. roseboom@amsterdamumc.nl).

\section{Declarations}

\section{Ethics approval and consent to participate}

The local Medical Ethics Committee of the Academic Medical Center of the University of Amsterdam approved the study, which was conducted according to the Helsinki declaration. All participants gave written informed consent.

\section{Consent for publication}

Not applicable.

\section{Competing interests}

The authors have no competing interests.

\section{Author details}

${ }^{1}$ SpHERE, Faculty of Health Sciences and Sport, University of Stirling, Stirling FK9 4LA, UK. ${ }^{2}$ School of Sport, Exercise and Rehabilitation Sciences, University of Birmingham, Birmingham, UK. ${ }^{3}$ Centre for Health and Social Care Research, Department of Physical Activity Sciences, Universitat de Vic-Universitat Central de Catalunya, Barcelona 08500, Vic, Spain. ${ }^{4}$ Department of Obstetrics \& Gynecology, Amsterdam University Medical Centers, University of Amsterdam, Amsterdam, The Netherlands. ${ }^{5}$ Department of Epidemiology and Data Science, Amsterdam University Medical Centers, University of Amsterdam, Amsterdam, The Netherlands. ${ }^{6}$ Department of Psychology \& Neuroscience, Baylor University, TX, Waco, USA.

Received: 14 December 2020 Accepted: 23 April 2021

Published online: 14 May 2021

\section{References}

1. Piercy KL, Troiano RP, Ballard RM, Carlson SA, Fulton JE, Galuska DA, et al. The physical activity guidelines for Americans. JAMA. 2018;320(19):2020-8. https://doi.org/10.1001/jama.2018.14854.

2. WHO guidelines on physical activity and sedentary behaviour. Geneva: World Health Organization; 2020. Licence: CC BY-NC-SA 3.0 IGO. https:// www.who.int/publications/i/item/9789240015128. Accessed 9 Mar 2021.

3. Bull FC, Al-Ansari SS, Biddle S, et al. World Health Organization 2020 guidelines on physical activity and sedentary behaviour. Br J Sports Med. 2020;54(24):1451-62. https://doi.org/10.1136/bjsports-2020-102955.

4. Teh KC, Aziz AR. Heart rate, oxygen uptake, and energy cost of ascending and descending the stairs. Med Sci Sport Exerc. 2002;34(4):695-699. doi: http://dx.doi.org/https://doi.org/10.1097/00005768-200204000-00021

5. Bassett DR, Vachon JA, Kirkland AO, Howley ET, Duncan GE, Johnson KR. Energy cost of stair climbing and descending on the college alumnus questionnaire. Med Sci Sports Exerc. 1997;29(9):1250-4. https://doi.org/10.1 097/00005768-199709000-00019.

6. Bartholomae E, Johnson Z, Moore J, Ward K, Kressler J. Reducing glycemic indicators with moderate intensity stepping of varied, short durations in people with pre-diabetes. J Sport Sci Med. 2018;17(4):680-5 http://www. jssm.org. Accessed March 11, 2021.

7. Boreham CAG, Kennedy RA, Murphy MH, Tully M, Wallace WFM, Young I. Training effects of short bouts of stair climbing on cardiorespiratory fitness, blood lipids, and homocysteine in sedentary young women. Br J Sports Med. 2005;39(9):590-3. https://doi.org/10.1136/bjsm.2002.001131.

8. Meyer P, Kayser B, Kossovsky MP, Sigaud P, Carballo D, Keller PF, et al. Stairs instead of elevators at workplace: Cardioprotective effects of a pragmatic 
intervention. Eur J Prev Cardiol. 2010;17(5):569-75. https://doi.org/10.1097/ HJR.0b013e328338a4dd.

9. Michael E, White MJ, Eves FF. Home-based stair climbing as an intervention for disease risk in adult females; a controlled study. Int J Environ Res Public Health. 2021;18(2):1-14. https://doi.org/10.3390/ijerph18020603.

10. Lee I-M, Paffenbarger RS. Physical activity and stroke incidence. Stroke. 1998; 29(10):2049-54. https://doi.org/10.1161/01.STR.29.10.2049.

11. Paffenbarger RS, Hyde R, Wing AL, Hsieh C. Physical activity, all-cause mortality, and longevity of college alumni. N Engl J Med. 1986;314(10):60513. https://doi.org/10.1056/nejm198603063141003.

12. Centers for Disease Control. Division of Nutrition, Physical Activity, and Obesity, National Center for Chronic Disease Prevention and Health Promotion. Worksite Physical Activity. https://www.cdc.gov/physicalactivity/ worksite-pa/index.htm. Accessed 17 Nov 2020.

13. Centre for Health Protection. Department of Health. THe Government of the Hong Kong Special Administrative Region. E-Resources - Benefits of Stair Climbing. https://www.chp.gov.hk/en/static/90006.html. Accessed 17 Nov 2020

14. NICE Guidance. Public Health Guideline PH13. Physical activity in the workplace. Published: 28 May 2008 https://www.nice.org.uk/guidance/ ph13. Accessed 17 Nov 2020

15. Mazloomzadeh S, Zarandi FK, Shoghli A, Dinmohammadi H. Metabolic syndrome, its components and mortality: a population-based study. Med J Islam Repub Iran. 2019;33(1):60-4 doi:10.341711/mjiri.33.11.

16. Lakka HM, Laaksonen DE, Lakka TA, Niskanen LK, Kumpusalo E, Tuomilehto $J$, et al. The metabolic syndrome and total and cardiovascular disease mortality in middle-aged men. J Am Med Assoc. 2002;288(21):2709-16. https://doi.org/10.1001/jama.288.21.2709.

17. de Rooij SR, Painter RC, Holleman F, Bossuyt PMM, Roseboom TJ. The metabolic syndrome in adults prenatally exposed to the Dutch famine. Am J Clin Nutr. 2007:86(4):1219-24. https://doi.org/10.1093/ajcn/86.4.1219.

18. Lumey LH, Ravelli ACJ, Wiessing LG, Koppe JG, Treffers PE, Stein ZA. The Dutch famine birth cohort study: design, validation of exposure, and selected characteristics of subjects after 43 years follow-up. Paediatr Perinat Epidemiol. 1993;7(4):354-67. https://doi.org/10.1111/j.1365-3016.1993.tb0041 5.x.

19. Ravelli AC, van der Meulen JH, Michels RP, Osmond C, Barker DJP, Hales CN, et al. Glucose tolerance in adults after prenatal exposure to famine. Lancet. 1998;351 (9097):173-7. doi: S0140673697072449 [pii]. https://doi.org/10.1016/ S0140-6736(97)07244-9.

20. de Rooij SR, Roseboom TJ. Further evidence for an association between self-reported health and cardiovascular as well as cortisol reactions to acute psychological stress. Psychophysiology. 2010;47(6):1172-5. doi: PSYP1023 [pii]. https://doi.org/10.1111/j.1469-8986.2010.01023.x.

21. Bakker B, Sieben I. Maten voor prestige, sociaal-economische status en sociale klasse voor de standaard beroepenclassificatie 1992. Soc Wet. 1997; 40:1-22.

22. Alberti KGMM, Eckel RH, Grundy SM, Zimmet PZ, Cleeman Jl, Donato KA, et al. Harmonizing the metabolic syndrome: a joint interim statement of the international diabetes federation task force on epidemiology and prevention; national heart, lung, and blood institute; American heart association; world heart federation; international atherosclerosis society; and international association for the study of obesity. Circulation. 2009;120(16): 1640-5. https://doi.org/10.1161/CIRCULATIONAHA.109.192644.

23. Roseboom T, de Rooij S, Painter R. The Dutch famine and its long-term consequences for adult health. Early Hum Dev. 2006;82(8):485-91. https:// doi.org/10.1016/j.earlhumdev.2006.07.001.

24. Moore J, Salmons H, Vinoskey C, Kressler J. A single one-minute, comfortable paced, stair-climbing bout reduces postprandial glucose following a mixed meal. Nutr Metab Cardiovasc Dis. 2020;30(11):1967-72. https://doi.org/10.1016/.numecd.2020.06.020.

25. Eves FF. Is there any Proffitt in stair climbing? A headcount of studies testing for demographic differences in choice of stairs. Psychon Bull Rev. 2014;21(1):71-7. https://doi.org/10.3758/s13423-013-0463-7.

26. Eves FF. When weight is an encumbrance; avoidance of stairs by different demographic groups. Smith L, ed. PLoS One. 2020;15(1):e0228044. doi: https://doi.org/10.1371/journal.pone.0228044

27. Eves FF, Puig-Ribera A. Learnt effects of environmental cues on transportrelated walking; disrupting habits with health promotion? Kato H, ed. PLoS One 2019;14(8):e0220308. doi:https://doi.org/10.1371/journal.pone.0220308.
28. Moore JM, Bartholomae E, Ward K, Kressler J. Postprandial glucose response moderation by cardiorespiratory fitness following short exercise bouts. J Sports Med Phys Fitness. 2020;60(5):764-9. https://doi.org/10.23736/S0022-4 707.20.10426-2.

29. Nocon M, Müller-Riemenschneider F, Nitzschke K, Willich SN. Review article: increasing physical activity with point-of-choice prompts - a systematic review. Scand J Public Health. 2010;38(6):633-8. https://doi.org/10.1177/14 03494810375865.

30. Bauman A, Milton K, Kariuki M, Fedel K, Lewicka M. Is there sufficient evidence regarding signage-based stair use interventions? A sequential meta-Analysis. BMJ Open. 2017;7(11). https://doi.org/10.1136/bmjopen-2016012459

31. Wu S, Cohen D, Shi Y, Pearson M, Sturm R. Economic analysis of physical activity interventions. Am J Prev Med. 2011;40(2):149-58. https://doi.org/10.1 016/j.amepre.2010.10.029.

32. Eves FF, Webb OJ, Mutrie N. A workplace intervention to promote stair climbing: greater effects in the overweight*. Obesity. 2006;14(12):2210-6. https://doi.org/10.1038/oby.2006.259.

33. Lewis AL, Eves FF. Specific effects of a calorie-based intervention on stair climbing in overweight commuters. Ann Behav Med. 2011;42(2):257-61. https://doi.org/10.1007/s12160-011-9283-z.

34. Janssen I, Ross R. Vigorous intensity physical activity is related to the metabolic syndrome independent of the physical activity dose. Int J Epidemiol. 2012:41(4):1132-40. https://doi.org/10.1093/ije/dys038.

35. Lakka TA, Laaksonen DE. Physical activity in prevention and treatment of the metabolic syndrome. Appl Physiol Nutr Metab. 2007;32(1):76-88. https:// doi.org/10.1139/H06-113

36. Laursen AH, Kristiansen OP, Marott JL, Schnohr P, Prescott E. Intensity versus duration of physical activity: Implications for the metabolic syndrome. A prospective cohort study. BMJ Open. 2012;2(5):e001711. https://doi.org/1 0.1136/bmjopen-2012-001711.

\section{Publisher's Note}

Springer Nature remains neutral with regard to jurisdictional claims in published maps and institutional affiliations.

\section{Ready to submit your research? Choose BMC and benefit from:}

- fast, convenient online submission

- thorough peer review by experienced researchers in your field

- rapid publication on acceptance

- support for research data, including large and complex data types

- gold Open Access which fosters wider collaboration and increased citations

- maximum visibility for your research: over $100 \mathrm{M}$ website views per year

At BMC, research is always in progress.

Learn more biomedcentral.com/submissions 